\title{
Atenção a Crianças e Adolescentes Vítimas de Violência Doméstica: Análise de um Serviço
}

\author{
Care of Children and Adolescents Suffering Domestic Violence: \\ Analysis of a Service
}

Suely F. Deslandes ${ }^{1}$

\begin{abstract}
DESLANDES, S. F. Care of Children and Adolescents Suffering Domestic Violence: Analysis of a Service. Cad. Saúde Pública, Rio de Janeiro, 10 (supplement 1): 177-187, 1994.
\end{abstract}

This paper provides a partial synthesis of the study entitled "Prevent and Protect: Analysis of an Organization to Aid Children Suffering from Domestic Violence". The study analyzes the work of Regional Centers Against Child Abuse (CRAMIs) in caring for children and adolescents who have been abused through intra-family violence. In technical and methodological terms, the study promotes a dialogue between quantitative and qualitative approaches, focusing on structure, processes, and representations present in the work of the CRAMIs, and characterizing the families assisted during the 1988-1992 period. It presents the profile of the families as well as the profile of the CRAMI's work. In light of the results, the study considers the potential contribution of CRAMIs to the implementation of actions in the public health system.

Key words: Domestic Violence; Violence Against Children; Infant Health; Adolescent Health

\section{INTRODUÇÃO}

Estudiosos afirmam que, quando se tratam dos aspectos de morbidade por violência contra crianças, o âmbito familiar é o locus privilegiado destes atos sociais (Azevedo \& Guerra, 1989; Guerra, 1985; Oliveira, 1989; Santos, 1987; Straus et al., 1980), infligidos quase sempre pelos próprios pais ou responsáveis e exercidos de forma variadas, isto é, através de violência física, violência sexual, violência psicológica, abandono intencional e negligência, ou seja, por um conjunto de atos violentos denominados "maus-tratos".

A questão dos maus-tratos pode ser encontrada em relatos clínicos que datam de fins do século XIX. Contudo, somente no século XX, mais precisamente na década de 60 , estes passam a constituir um problema de saúde, reconhecido sob a epígrafe "síndrome do bebê espancado - SIBE" (the battered baby syndrome). Uma década após sua definição, alguns países

${ }^{1}$ Centro Latino-Americano de Estudos de Violência e Saúde da Fundação Oswaldo Cruz. Av. Brasil, 4036, sala 702, Rio de Janeiro, RJ, 21040-361, Brasil. reconhecem, em nível mais amplo, os maus-tratos como um sério problema de saúde pública. Nos E.U.A., por exemplo, na década de 70 são criados programas nacionais de prevenção primária e secundária, além de centrais de denúncias, tornando público um problema considerado "particular".

Em inquérito realizado nos E.U.A., em 1985, apontou-se que $62 \%$ dos pais utilizavam a agressão, materializada em empurrões, tapas e, até, uso de armas, no trato com os filhos (NCCAPR, 1992). Segundo o National Incidence Study, ao longo do ano de 1986, nos E.U.A., 311.500 crianças, ou 4,9 em cada 1.000, foram abusadas fisicamente; 188.100 crianças, ou 3 em 1.000, foram abusadas emocionalmente; 133.600 crianças, ou 2,1 em 1.000, foram abusadas sexualmente; e 507.700, ou 8,1 em 1.000, foram vítimas de negligência física (U.S. Department of Health and Human Services, 1991).

No Brasil, somente na década de 80 a temática da violência emerge como um problema de saúde pública, ampliando o espaço para se discutir a questão dos maus-tratos. Assim, ainda se desconhece a freqüência exata dos casos de 
abuso contra a criança e o adolescente, pois conta-se basicamente com o registro dos poucos serviços existentes no país para a identificação e atendimento das famílias que praticam maustratos.

A Associação Brasileira de Crianças Abusadas e Negligenciadas estima a ocorrência de 4,5 milhões de crianças vítimas de abuso e negligência por ano no país. Estatísticas do Serviço de Advocacia da Criança (SAC) da Secretaria do Menor de São Paulo registraram o atendimento de 6.056 casos de crianças vítimas de violência na Capital, no período de 1988 a 1990. Destes, 64\% eram casos de violência doméstica. A Associação Brasileira de Proteção à Infância (Abrapia), no período de 1991 a março de 93, realizou 3.981 atendimentos de crianças vitimizadas no lar no Rio de Janeiro.

Apesar da inexatidão dos dados, o problema tem se mostrado relevante, pela consciência da freqüência com que se apresenta e pelo reconhecimento científico das consequiências deletérias para o crescimento e desenvolvimento das crianças vitimizadas. Há hoje, no Brasil, o desenvolvimento de uma consciência social em torno do tema da proteção à infância. Apontamse, portanto, os desafios de conhecer melhor o fenômeno dos maus-tratos na realidade brasileira como estratégia para encontrar formas de prevenção.

Neste trabalho, portanto, parte-se da premissa de que, para sugerir ações ao Sistema Público de Saúde, é necessário primeiro delinear o perfil dos sujeitos sociais envolvidos na prática dos maus-tratos, bem como avaliar as formas de atuação que, embora poucas e iniciantes, já existem no país. No estudo do qual se origina o presente artigo analisou-se a atuação de uma organização pioneira no atendimento de famílias que praticam a violência doméstica: os Centros Regionais de Atenção aos Maus-Tratos na Infância (Cramis), organizações não-governamentais que existem há 9 anos em vários municípios de São Paulo.

O Crami foi fundado em 1985, em Campinas, e posteriormente implantado em outros municípios do Estado de São Paulo: Itapira, Piracicaba, Botucatu, Sorocaba, São José do Rio Preto, Santo André e Bauru. Cada Crami regional privilegia projetos de atuação segundo as necessidades da comunidade a que atende e segundo suas possibilidades de infra-estrutura.

O Crami dirige-se ao atendimento de crianças vítimas de maus-tratos e de suas famílias, tendo como objetivos a proteção e a assistência à criança vítima de maus-tratos. Sua atuação visa, fundamentalmente, a proteção, o registro e o tratamento dos casos, bem como a promoção da criança junto à família.

O Crami tem como ação básica o Programa Emergencial, o qual é gerador dos demais programas: nele a criança e o adolescente vítimas de maus-tratos são atendidos dentro do âmbito familiar. A abordagem no atendimento "é realizada com a família e as crianças e adolescentes, efetuando um trabalho de conscientização e sensibilização" (Crami, 1992: 02). Através do Programa Emergencial, os profissionais registram os casos notificados; fazem visitas domiciliares e diagnósticos; atuam nas famílias por meio de orientação com assistentes sociais e psicólogas; e encaminham as famílias aos recursos de saúde, de assistência social e jurídicos da comunidade. O Programa se processa nos seguintes momentos: 1) notificação, através de telefonema, carta ou pessoalmente; 2) encaminhamento ao serviço social, que estabelece o grau de prioridade para a entrevista em domicílio; 3) verificação da situação real da criança e da família em relação ao problema; 4) diagnóstico; 5) encaminhamentos.

O Crami fundamenta-se principalmente numa premissa de "descentralização de ações, envolvendo diferentes instituições sociais numa gestão de co-responsabilidades na proteção da criança e adolescentes vítimas de violência doméstica" (Crami, 1992: 02).

A família "maltratante" é compreendida como "partícipe de um problema que envolve uma complexidade de determinantes culturais, sócio-psicológicos, econômicos, religiosos e psiquiátricos, cujas diferenças regionais interferem na sua compreensão" (Santos, 1991). Assim, o Crami opta por uma ação educativa e não-criminalizadora, entendendo que a melhor instituição para a proteção da criança é sua própria família e que as diferentes características regionais devem conduzir a uma atuação regionalizada diferenciada. 


\section{METODOLOGIA EMPREGADA}

A opção metodológica da pesquisa fundamentou-se numa abordagem que conjugou a análise quantitativa de dados referentes a 1.645 famílias atendidas, com a análise qualitativa de 45 depoimentos dos atores sociais envolvidos na atuação: técnicos dos Cramis, famílias e profissionais de outras instituições que participam nos encaminhamentos. $\mathrm{O}$ estudo focalizou a estrutura, os processos e as representações presentes na atuação dos Cramis, além de caracterizar as famílias atendidas no período de 1988 a 1992.

A análise qualitativa foi um procedimento importante nesta investigação, auxiliando a compreensão e sugerindo novas questões à abordagem quantitativa. Buscou-se dar conta tanto das relações que constituem a base estrutural quanto das representações sociais que retêm a vivência destas relações experimentadas pelos atores e as significações por eles atribuídas às suas ações.

Para definir a amostra quantitativa obteve-se, primeiramente, a população atendida nos vários Cramis ao longo do período. Em seguida, foram analisadas as amostras pilotos, a partir da definição das variáveis de interesse, determinando-se o tamanho amostral de cada um dos Cramis. Para o cálculo do tamanho da amostra foi utilizada, nos Cramis de Campinas e Bauru, a fórmula indicada por Tortora (1978), que se aplica a distribuições multinomiais. Para os outros Cramis (Piracicaba, Botucatu, Itapira, Sorocaba e São José do Rio Preto) foi utilizada a fórmula que se aplica a distribuições binomiais. Em virtude de as distribuições multinomiais gerarem um tamanho de amostra muito grande, aumentando ainda mais o tempo para a análise dos casos, optou-se pela utilização de duas fórmulas diferentes (binomial e multinomial), embora a análise multinomial fosse a mais indicada, por permitir estimar para mais de duas categorias de abuso. A amostra foi composta da seguinte maneira: Campinas, 452 casos; Piracicaba, 228; Botucatu, 169; Bauru, 272; São José do Rio Preto, 239; Itapira, 113; e Sorocaba, 172.

As freqüências e proporções, bem como os cruzamentos de variáveis, foram obtidas excluindo-se respostas ignoradas nos registros, ou seja, os cálculos estatísticos foram feitos somente com as informações realmente verificadas.

Para os cruzamentos de variáveis, freqüências e proporções foi utilizado o software Epi-Info, versão 5.0, enquanto para os testes de concordância o programa "CONCORD” (Klein \& Coutinho, 1988).

Em virtude de o plano amostral do estudo ter considerado a população isolada de cada Crami (amostragem aleatória simples), e não a população de todos os Cramis como uma única população, não se pôde estimar os resultados para todos os Cramis em conjunto, e sim estimá-los separadamente.

Dos Cramis estudados, dois (Sorocaba e Itapira) apresentaram sérias deficiências no registro. Esses não foram excluídos, mas seus dados merecem ser relativizados.

\section{CARACTERIZANDO UMA REALIDADE COMPLEXA}

\section{A Família}

As condições econômicas das famílias atendidas neste serviço apontam que a maioria absoluta (sempre acima de 70,0\%) percebe uma renda familiar variando entre "menos de um salário mínimo (SM)" a "três salários mínimos". Dessas famílias investigadas, cerca de 80,0\% têm dois ou mais filhos, agravando a situação de pobreza constatada (Quadro 1).

Vale comentar este aspecto mais demoradamente. A literatura clássica sobre o tema afirma que todas as classes sociais vivenciam o problema da violência doméstica (Straus et al., 1980; Garbarino \& Gilliam, 1981). Contudo, é nas classes populares que se encontram os maiores percentuais de registros colhidos. Entretanto, não se pode esquecer que a concentração de renda no Brasil tem crescido cada vez mais (Saboia, 1993). Dados da Pesquisa Nacional por Amostra de Domicílios - PNAD (IBGE, 1990) apontam que, no ano de 1989, 30,7\% das famílias brasileiras recebiam rendimento mensal na faixa de 0 a 2 salários mínimos, e uma vez estendido o rendimento familiar à faixa de $0 \mathrm{a}$ 5 salários mínimos, este percentual eleva-se a 
QUADRO 1. Características Familiares das Crianças e Adolescentes Atendidos no Cramis, 1988-1992

\begin{tabular}{|c|c|c|c|c|c|c|c|}
\hline \multirow[b]{2}{*}{$\begin{array}{l}\text { Características } \\
\text { Familiares }\end{array}$} & \multicolumn{7}{|c|}{ C $\mathrm{R}$ A $\mathrm{M}$ I } \\
\hline & Campinas & Botucatu & Itapira & Piracicaba & Bauru & São José & Sorocaba \\
\hline \multicolumn{8}{|l|}{ Renda Familiar } \\
\hline Faixa de 1 a 3 SMs & $\begin{array}{c}71,3 \\
N=268\end{array}$ & $\begin{array}{c}74,8 \\
\mathrm{~N}=119\end{array}$ & $\begin{array}{c}83,7 \\
\mathrm{~N}=49\end{array}$ & $\begin{array}{c}78,7 \\
N=183\end{array}$ & $\begin{array}{c}82,1 \\
\mathrm{~N}=168\end{array}$ & $\begin{array}{c}98,6 \\
N=177\end{array}$ & $\begin{array}{c}61,9 \\
\mathrm{~N}=21\end{array}$ \\
\hline \multicolumn{8}{|l|}{ Presença de 2 ou Mais } \\
\hline Filhos & $\begin{array}{c}79,0 \\
\mathrm{~N}=419 \\
\end{array}$ & $\begin{array}{c}84,4 \\
\mathrm{~N}=167 \\
\end{array}$ & $\begin{array}{c}82,1 \\
\mathrm{~N}=106 \\
\end{array}$ & $\begin{array}{c}78,6 \\
\mathrm{~N}=215 \\
\end{array}$ & $\begin{array}{c}80,7 \\
\mathrm{~N}=269 \\
\end{array}$ & $\begin{array}{c}81,1 \\
\mathrm{~N}=228 \\
\end{array}$ & $\begin{array}{c}83,7 \\
\mathrm{~N}=160 \\
\end{array}$ \\
\hline $\begin{array}{l}\text { Número Total } \\
\text { de Crianças Agredidas }\end{array}$ & $\begin{array}{c}891 \\
N=450 \\
\end{array}$ & $\begin{array}{c}323 \\
\mathrm{~N}=169 \\
\end{array}$ & $\begin{array}{c}241 \\
\mathrm{~N}=111 \\
\end{array}$ & $\begin{array}{c}422 \\
N=228 \\
\end{array}$ & $\begin{array}{c}541 \\
\mathrm{~N}=270 \\
\end{array}$ & $\begin{array}{c}363 \\
\mathrm{~N}=238 \\
\end{array}$ & $\begin{array}{c}416 \\
\mathrm{~N}=172 \\
\end{array}$ \\
\hline \multicolumn{8}{|l|}{$\begin{array}{l}\text { Pais que Residem com } \\
\text { a Criança }\end{array}$} \\
\hline Pai e Mãe & 47,1 & 48,5 & 39,8 & 38,2 & 40,8 & 46,9 & 38,6 \\
\hline Somente Mãe & 36,3 & 31,4 & 38,1 & 41,2 & 12,3 & 37,2 & 38,66 \\
\hline & $\mathrm{N}=437$ & $\mathrm{~N}=169$ & $\mathrm{~N}=113$ & $\mathrm{~N}=228$ & $\mathrm{~N}=272$ & $\mathrm{~N}=239$ & $\mathrm{~N}=171$ \\
\hline
\end{tabular}

Fonte: Cramis de Campinas, Botucatu, Itapira, Piracicaba, Bauru, São José do Rio Preto e Sorocaba, 1988-1992.

61,2\% das famílias. Logo, não há contradição no fato de as "famílias pobres", por serem mais numerosas, contribuírem com a maioria dos casos registrados. Por outro lado, a análise atual da "etiologia dos maus-tratos" aponta para uma perspectiva dinâmica onde uma rede de fatores estão interligados, inclusive os socio-econômicos, que são de grande importância. Cabe, contudo, lembrar o nível elevado de pressões, estresse e frustrações que a miséria traz. Seria até ingênuo descartar tais fatos, porém se as análises não cotejarem as questões culturais, psicológicas e sociais, corre-se o risco chegar a conclusões eminentemente ideológicas, mais uma vez com prejuízos para as classes populares e camadas de baixa renda.

Outro aspecto importante é o acesso mais "facilitado" dos serviços sociais às famílias mais pobres, pois essas convivem com constantes e variadas intervenções nas suas vidas privadas (do poder público, dos poderes locais, dos poderes paralelos). As famílias de maior poder aquisitivo geralmente estão muito menos à mercê de serem notificadas, pois, ao utilizarem serviços privados de atendimento médico, psicológico e de educação, "pagam" também pela discrição.

A própria população atendida pelos Cramis é predominantemente composta por famílias de baixa renda, fato que reforça tais hipóteses. $\mathrm{Na}$ realidade, este campo de discussões ainda carece de pesquisas com metodologias suficientemente adequadas à complexidade do tema.

Quanto à composição familiar, verificou-se que, em todos os Cramis, $40,0 \%$ a $50,0 \%$ das famílias investigadas não contam com a presença de ambos os pais, e em cerca de $30,0 \%$ a $40,0 \%$ das famílias a criança vive somente com a mãe.

Estudo de Gil (1978) também verifica a ausência do pai em cerca de $50 \%$ de sua amostra. Além disso, dados recentes para o Brasil apontam para o aumento de famílias chefiadas por mulheres em populações de baixa renda. Portanto, este perfil de separações conjugais também indica um processo agravante da 
situação de pobreza relacionado à falta da figura do pai, podendo o mesmo ainda estar associado à violência doméstica.

Em menos da metade das famílias investigadas foi possível, através da história de atendimento, recuperar os motivos alegados pelos familiares para explicar o abuso cometido. Percebeu-se que a maioria das justificativas recai sobre o comportamento do agressor, enfatizando-se o envolvimento deste com alguma espécie de drogadição. As explicações que apontam a própria criança como "responsável" pelo abuso indicam o seu comportamento rebelde e a necessidade de educá-las, aparecendo com menor frequiência a explicação de "distúrbios comportamentais" da criança.

São vários os estudos que buscam compreender as possíveis explicações para o abuso. Guerra (1985), analisando casos de maus-tratos, aponta que, nas famílias onde acontecem, a agressão física desempenha papel central na educação dos filhos. A drogadição, especialmente o alcoolismo, também é referendada na literatura como um importante fator desencadeante dos maus-tratos (Giovannoni \& Becerra, 1982; Monteiro, 1992).

\section{A Criança e o Adolescente Vitimizados}

As faixas etárias das crianças vitimizadas foram, mais frequientemente, a de 5-9 anos e a de 10-14 anos. Entretanto, separando-se a faixa de 0-6 anos, percebe-se que esta ocupa um percentual muito elevado, de cerca de $41 \%$ a $45 \%$ das crianças atendidas em todos os Cramis.

Tal observação confirma os estudos nacionais e internacionais sobre o tema, que apontam as crianças menores, sobretudo as de $0-6$ anos e de 6-9 anos, como vítimas mais freqüentes da violência doméstica (Gil, 1978; Justice \& Justice, 1976; Ruiz, 1985). Contudo, os dados dos Cramis apresentados sugerem, ainda, que a faixa de 10-14 anos é alvo significativo dos maus-tratos.

A sutil diferença observada entre os sexos é também encontrada por alguns autores, que concluem que o sexo não é em si um fator associado à perpetração dos maus-tratos (Justice \& Justice, 1976). Outros estudos, porém, encontram um maior número de crianças do sexo masculino como alvo das práticas abusivas (Gelles, 1979).

O primogênito é a vítima preferencial na maioria dos casos em todos os Cramis (Quadro 2). A literatura sobre as características da criança/adolescente abusada enfatiza a escolha, ainda que inconsciente, de um filho específico para alvo dos maus-tratos. Esta criança/adolescente seria eleita por suas características pessoais ou a ela atribuídas por seus pais (Giovannoni \& Becerra, 1982; Oates et al., 1984). No presente estudo, porém, verificou-se, ainda, uma alta tendência da prática abusiva extensiva a mais de um dos filhos da família.

QUADRO 2. Características das Crianças/Adolescentes Vitimizadas Atendidas nos Cramis, 1988 a 1992

\begin{tabular}{|c|c|c|c|c|c|c|c|}
\hline \multirow{2}{*}{\begin{tabular}{|l} 
Características \\
da Criança/Adolescente \\
Vitimizado \\
\end{tabular}} & \multicolumn{7}{|c|}{ C R A M I } \\
\hline & Campinas & Botucatu & Itapira & Piracicaba & Bauru & São José & Sorocaba \\
\hline \multicolumn{8}{|l|}{ Faixa Etária } \\
\hline 5 a 9 & 35,1 & 34,5 & 32,1 & 32,2 & 31,0 & 36,4 & 33,1 \\
\hline 0 a 6 & 41,6 & 41,2 & 43,1 & 44,9 & 42,1 & 41,8 & 30,2 \\
\hline \multirow[t]{2}{*}{10 a 14} & 27,5 & 33,3 & 32,1 & 26,0 & 31,4 & 30,5 & 39,1 \\
\hline & $\mathrm{N}=447$ & $\mathrm{~N}=165$ & $\mathrm{~N}=109$ & $\mathrm{~N}=227$ & $\mathrm{~N}=261$ & $\mathrm{~N}=239$ & $\mathrm{~N}=169$ \\
\hline \multicolumn{8}{|l|}{ Sexo } \\
\hline Masculino & 51,5 & 49,7 & 46,9 & 50,5 & 51,1 & 50,2 & 48,3 \\
\hline \multirow[t]{2}{*}{ Feminino } & 48,5 & 50,3 & 53,1 & 49,5 & 48,9 & 49,8 & 51,7 \\
\hline & $\mathrm{N}=452$ & $\mathrm{~N}=169$ & $\mathrm{~N}=113$ & $\mathrm{~N}=228$ & $\mathrm{~N}=268$ & $\mathrm{~N}=239$ & $\mathrm{~N}=172$ \\
\hline \multicolumn{8}{|l|}{ Posição } \\
\hline \multirow[t]{2}{*}{ Filho biológico } & 77,4 & 80,2 & 76,6 & 80,7 & 76,8 & 76,6 & 77,6 \\
\hline & $N=394$ & $N=167$ & $\mathrm{~N}=111$ & $\mathrm{~N}=228$ & $N=272$ & $\mathrm{~N}=239$ & $\mathrm{~N}=170$ \\
\hline \multirow[t]{2}{*}{ Primogênito } & 43,7 & 40,9 & 48,5 & 41,0 & 38,7 & 37,6 & 47,4 \\
\hline & $\mathrm{N}=398$ & $\mathrm{~N}=157$ & $\mathrm{~N}=99$ & $\mathrm{~N}=210$ & $\mathrm{~N}=256$ & $\mathrm{~N}=229$ & $\mathrm{~N}=152$ \\
\hline
\end{tabular}

Fonte: Cramis de Campinas, Botucatu, Itapira, Piracicaba, Bauru, São José do Rio Preto e Sorocaba, 1988 a 1992. 
Outra observação importante quanto à situação do filho abusado é que a maioria destes (cerca de $77 \%$ a $80 \%$ ) é filho biológico de seu agente agressor.

\section{O Agente Agressor}

O agressor mais freqüente no conjunto global de maus-tratos praticados foi a mãe, estando presente em $31 \%$ a $48 \%$ dos atendimentos nos diferentes Cramis (Quadro 3).

Este destaque da mãe enquanto agressor é referendado por muitos estudos (Gelles, 1979; Gil, 1978; Meyer, 1988), merecendo ser discutido. A mãe, via de regra, é aquela que mais tempo passa junto aos filhos, cabendo-lhe culturalmente o manejo das decisões cotidianas e a convivência doméstica. Por outro lado, como se viu no estudo qualitativo, a permanência no lar muitas vezes acarreta sérias frustrações para a mulher, pois esta se vê obrigada, por ter filhos pequenos ou por determinação do companheiro, a se restringir à "vida doméstica", quando também desejaria para si outros horizontes de realização pessoal. Condon (1986) afirma que, uma vez igualado o tempo de permanência junto aos filhos, o pai se configura como agressor mais freqüiente.

Quanto à inserção no mercado de trabalho, observa-se que, quando o agressor é o pai, a maioria (sempre mais de 50\%) está empregada. Quando o agressor é a mãe, observa-se que a maioria é "do lar" ou está desempregada.

Grande parte dos estudos sobre a causalidade dos maus-tratos indica, entre muitos outros fatores, o desemprego e a baixa renda como responsáveis pela frustração e pelo estresse, que, por sua vez, podem propiciar a prática abusiva (Justice \& Justice, 1976; Azevedo \& Guerra, 1989; Ruiz, 1985; Straus et al., 1980). Há ainda que se discutir as condições de trabalho (extensa jornada, insalubridade, disciplina rígida, entre outros) como fatores que podem levar ao estresse e à frustração pessoal.

QUADRO 3. Caracterização do Agente Agressor das Famílias Atendidas pelos Cramis, 1988-1992

\begin{tabular}{|c|c|c|c|c|c|c|c|}
\hline \multirow{2}{*}{$\begin{array}{l}\text { Características } \\
\text { do Agente Agressor }\end{array}$} & \multicolumn{7}{|c|}{ C C R A I } \\
\hline & Campinas & Botucatu & Itapira & Piracicaba & Bauru & São José & Sorocaba \\
\hline \multicolumn{8}{|l|}{ Agressor } \\
\hline Mãe & 42,8 & 31,7 & 40,7 & 48,0 & 46,6 & 35,5 & 41,4 \\
\hline Pai & 27,8 & 28,6 & 20,9 & 15,7 & 19,7 & 32,0 & 26,4 \\
\hline \multirow[t]{2}{*}{ Pais* } & 77,4 & 82,0 & 82,6 & 83,4 & 84,5 & 77,5 & 78,6 \\
\hline & $\mathrm{N}=366$ & $\mathrm{~N}=161$ & $\mathrm{~N}=86$ & $\mathrm{~N}=204$ & $\mathrm{~N}=232$ & $\mathrm{~N}=231$ & $\mathrm{~N}=140$ \\
\hline \multicolumn{8}{|l|}{$\begin{array}{l}\text { Inserção no Mercado } \\
\text { de Trabalho }\end{array}$} \\
\hline Pai Empregado & 73,3 & 72,5 & 83,3 & 74,1 & 52,3 & 82,9 & 70,0 \\
\hline \multirow[t]{2}{*}{ Pai Não Trabalha } & 22,1 & 22,5 & 11,1 & 25,9 & 29,5 & 8,6 & 16,7 \\
\hline & $\mathrm{N}=86$ & $\mathrm{~N}=40$ & $\mathrm{~N}=18$ & $\mathrm{~N}=27$ & $\mathrm{~N}=44$ & $\mathrm{~N}=70$ & $\mathrm{~N}=30$ \\
\hline Mãe Empregada & 45,3 & 60,5 & 48,4 & 41,0 & 42,7 & 40,8 & 36,0 \\
\hline \multirow[t]{2}{*}{ Mãe Não Trabalha** } & 48,9 & 34,9 & 45,2 & 55,1 & 56,3 & 56,4 & 58,0 \\
\hline & $\mathrm{N}=137$ & $\mathrm{~N}=43$ & $\mathrm{~N}=31$ & $\mathrm{~N}=78$ & $\mathrm{~N}=103$ & $\mathrm{~N}=71$ & $\mathrm{~N}=50$ \\
\hline
\end{tabular}

\footnotetext{
* Pai + mãe + ambos + outros agressor associado a um dos pais.

** Desempregada ou do lar

Fonte: Cramis de Campinas, Botucatu, Itapira, Piracicaba, Bauru, São José do Rio Preto e Sorocaba, 1988-1992.
} 


\section{Tipos de Maus-tratos Praticados}

Como pode ser verificado no Quadro 4, o tipo de abuso predominante entre os notificados foi o físico, seguido de negligência/abandono.

Esta preponderância do abuso físico muito provavelmente associa-se, como já observado, a um modelo cultural arraigado que justifica e reforça a punição corporal como medida educativa.

A relevância da percentagem para a negligência, ao que tudo indica, está associada a situações limítrofes entre pobreza e maus-tratos. Ou seja, uma vez que a negligência se define pela omissão no trato dos cuidados e necessidades da criança, a reconhecida ausência de condições econômicas dessas famílias muitas vezes dificulta um julgamento mais preciso entre prática abusiva e impossibilidade de prover a atenção.

O percentual dos casos de abuso sexual, um dos menos notificados em todos os Cramis, apresenta-se baixo se comparado às outras modalidades de violência. No entanto, a pouca significância do dado quantitativo revela sua significância qualitativa. Ou seja, a escassa notificação está associada ao tabu cultural que cerca as questões acerca da sexualidade.

\section{Caracterização da Atuação dos Cramis}

Os principais notificantes dos abusos nos diferentes Cramis foram a própria família, anônimos e a comunidade. A participação dos serviços de saúde nas notificações variou em torno de $7 \%$ a $24 \%$. O maior percentual observado $(24,3 \%)$ foi no município de São José do Rio Preto, o único Crami que funciona dentro de uma unidade de saúde, sendo ela própria um notificante privilegiado (Quadro 5).

Vale ressaltar a baixa participação da escola (aparecendo entre $4 \%$ e $10 \%$ no conjunto de notificantes), uma instituição cujos profissionais são apontados pelo Estatuto da Criança e do Adolescente como em situação de obrigatoriedade de notificação de qualquer abuso (confirmado ou suspeito) contra menores de até 17 anos de que tenham conhecimento (MS, 1991). A desinformação, o medo de se envolver em "conflitos particulares", o receio de represálias e o não-reconhecimento do papel do professor neste problema são fatores que colaboram para este quadro, o que sugere a necessidade de programas de capacitação para estes profissionais, visando o reconhecimento de seu papel diante do problema, a identificação dos casos e

QUADRO 4. Tipos de Maus-Tratos Praticados Contra Crianças/Adolescentes Atendidas pelos Cramis, 1988-1992

\begin{tabular}{|lcccccccc}
\hline \hline & \multicolumn{7}{c}{ C R A M I } \\
\cline { 2 - 8 } $\begin{array}{l}\text { Tipo de Maus-Tratos } \\
\text { Praticados }\end{array}$ & Campinas & Botucatu & Itapira & Piracicaba & Bauru & São José & Sorocaba \\
\hline Abuso Físico & 43,1 & 29,9 & 32,5 & 31,8 & 24,2 & 48,9 & 45,5 \\
\hline Negligência/Abandono & 23,5 & 21,0 & 35,0 & 25,4 & 19,7 & 19,2 & 14,9 \\
\hline Abuso Psicológico & 16,4 & 6,0 & 9,6 & 4,6 & 6,5 & 5,1 & 1,9 \\
\hline Abuso Sexual & 7,7 & 2,4 & 3,6 & 3,2 & 3,6 & 7,2 & 9,1 \\
\hline Outros Tipos & 9,3 & 1,8 & 2,4 & 1,8 & 0,8 & 0,5 & 1,9 \\
\hline+ de 1 Tipo Associado & " & 38,9 & 16,9 & 33,2 & 45,2 & 19,1 & 26,7 \\
\hline & $\mathrm{N}=440$ & $\mathrm{~N}=167$ & $\mathrm{~N}=83$ & $\mathrm{~N}=217$ & $\mathrm{~N}=248$ & $\mathrm{~N}=235$ & $\mathrm{~N}=154$ \\
\hline \hline
\end{tabular}

Fonte: Cramis de Campinas, Botucatu, Itapira, Piracicaba, Bauru, São José do Rio Preto e Sorocaba, 1988-1992. 
QUADRO 5. Notificantes dos Casos Atendidos pelos Cramis, 1988-1992

\begin{tabular}{|lccccccc}
\hline \hline $\begin{array}{l}\text { Características } \\
\text { da Atuação } \\
\text { dos Cramis } \\
\text { Notificante }\end{array}$ & Campinas & Botucatu & Itapira & Piracicaba & Bauru & São José & Sorocaba \\
\cline { 2 - 8 } & & & & & & & \\
\cline { 2 - 8 } Família & 21,3 & 26,3 & 24,3 & 26,1 & 20,8 & 17,0 & 10,7 \\
\hline Anônimo & 25,2 & 1,8 & 23,4 & 27,4 & 19,2 & 11,7 & 35,7 \\
\hline Comunidade & 17,1 & 18,0 & 15,3 & 19,0 & 20,4 & 23,5 & 13,7 \\
\hline Serviços de Saúde & 15,3 & 15,6 & 9,9 & 7,1 & 8,5 & 24,3 & 10,1 \\
\hline $\begin{array}{l}\text { Própria Criança/ } \\
\text { Adolescente }\end{array}$ & 1,3 & 1,8 & 2,7 & 2,2 & 0,8 & 0,4 & 1,2 \\
\hline Escola & 4,0 & 3,6 & 3,6 & 2,7 & 6,5 & 1,7 & 10,7 \\
\hline Outras Instituições & 15,8 & 32,9 & 20,8 & 15,5 & 23,8 & 21,4 & 17,9 \\
\hline & $\mathrm{N}=451$ & $\mathrm{~N}=167$ & $\mathrm{~N}=111$ & $\mathrm{~N}=226$ & $\mathrm{~N}=260$ & $\mathrm{~N}=230$ & $\mathrm{~N}=168$ \\
\hline \hline
\end{tabular}

Fonte: Cramis de Campinas, Botucatu, Itapira, Piracicaba, Bauru, São José do Rio Preto e Sorocaba, 1988-1992.

o encaminhamento aos serviços adequados (Assis, 1991). Este fato reforça a tese de que a maioria dos casos de maus-tratos contra crianças e adolescentes que chegam às instituições de saúde e das escolas não é reportada, a não ser quando a severidade da agressão beira extremos.

Constatou-se que os Cramis prestam um atendimento emergencial, realizando, via de regra, de uma a cinco ações por caso. O número de ações vê-se restringido, sobretudo, por limitações infra-estruturais do serviço. Os atendimentos posteriores, que seriam necessários para o acompanhamento das famílias, são destinados aos casos "mais complexos". A grande maioria das notificações, em todos os Cramis, teve um pronto atendimento, isto é, logo na primeira semana.

Todos os Cramis envolveram outras instituições no atendimento às famílias (variando entre $58 \%$ a $82 \%$ dos casos). Dessas instituições envolvidas, entre $24 \%$ e $42 \%$ foram serviços de saúde (na sua maioria hospitais).

Pode-se inferir, portanto, que a orientação do Crami tem um papel mobilizador fundamental ao buscar envolver outros recursos comunitários (creches, escolas, serviços de saúde, cesta básica, entre outros). O que se deduz é que, além do abuso, a maioria das famílias convive com outros problemas, geralmente de natureza sócio-econômica, agravando a situação de conflito familiar.

Os procedimentos mais frequientes dos Cramis em relação à criança foram as conversas e orientações com os agentes da própria instituição e os recursos dos serviços de saúde. A comparação dos dados, associada à observação de campo, indica que a maior base dos procedimentos do serviço dos Cramis, no que diz respeito ao agente agressor, é a sua própria orientação. Esta opção por "contar consigo mesmo" agiliza o trabalho e o torna mais auto-suficiente diante do frágil aparelhamento de uma rede de atuação em maus-tratos envolvendo outros serviços. A análise qualitativa referente a este aspecto trouxe uma nova dimensão às características do serviço. Ao entrevistar as famílias atendidas, foi muito significativa a valorização que estas concederam à orientação dos Cramis, enfatizando a positividade deste tipo de ação. Segundo os entrevistados, na orientação falava-se sobre assuntos que desconheciam, como características do crescimento da criança, necessidade de afeto 
nas relações entre pais e filhos, conseqüências presentes e futuras dos maus-tratos, levando-os a repensar visões de convivência familiar consolidadas e criando um clima de apoio.

Pode-se observar que, na grande maioria dos atendimentos, em todos os Cramis, a criança/ adolescente vitimizada e o agente agressor permaneceram junto à sua família original após a atuação do serviço (em cerca de $75 \%$ a $88 \%$ dos atendimentos). Estes fatos reforçam positivamente as premissas que têm orientado as atuações mais consolidadas no país e no exterior: a família deve ser preservada e tratada como alvo de atenção, sendo a maioria o melhor ambiente para a criança, desde que devidamente atendida e apoiada (Olds, 1990). É importante lembrar, como já tem sido feito em outros trabalhos (Minayo, 1993), que se assume aqui o termo família dentro de uma conceituação, isto é, como espaço das relações primárias que permite à criança crescer e se desenvolver física, emocional e espiritualmente, não podendo o mesmo ser confundido apenas com a família nuclear.

Observou-se também um baixo percentual de reincidências notificadas ( de $10 \%$ a $24 \%$ dos casos), na sua maioria cerca de 6 meses depois de encerrada a atuação. Especula-se que a ação do serviço ou foi suficientemente eficaz ou não desenvolveu mecanismos adequados para captar as reincidências, não sendo possível comprovar nenhuma das hipóteses. Contudo, acredita-se que, dada a existência de uma rede de notificação, ainda que precária, aumentam as probabilidades de que um caso reincidente seja novamente reportado.

Os depoimentos das famílias atendidas e dos profissionais de outras instituições, bem como o aumento considerável de novas notificações a cada mês, indicam que o experiência deste serviço conquistou uma grande credibilidade nos municípios em que atua. A ação dos Cramis aponta para uma atuação possível em que a família é tida como alvo da atenção. Outra contribuição relevante dos Cramis é o papel que estes desempenham em mobilizar e conscientizar outros profissionais dos serviços públicos (especialmente os de saúde) em relação à importância da prevenção dos maus-tratos. Por outro lado, eles também possuem limitações, sobretudo por motivos infra-estrutu- rais, tais como: demanda muito grande de atendimentos para poucos profissionais, o que leva a triagens dos casos que terão maior prioridade, prejudicando outros atendimentos e comprometendo o acompanhamento das famílias; evasão e grande rotatividade dos agentes dos Cramis, devido à ausência de estabilidade financeira destas instituições; e falta de um treinamento em serviço e de uma supervisão do atendimento na maioria dos Cramis.

\section{CONCLUSÕES}

A avaliação dos Cramis, através de sua experiência, traz várias contribuições para se pensar como atuar no problema da violência doméstica.

A mais básica para este tipo de ação é o conhecimento da população demandante. A análise dos casos atendidos pelos Cramis ao longo dos últimos 4 anos pode ser um primeiro passo, ainda que básico, para esta compreensão acerca das principais características das famílias que vivenciam os maus-tratos. A ausência desta informação compromete tanto a identificação de novos casos como a atuação nos casos já conhecidos.

Quanto à atuação propriamente dita, algumas "lições" podem ser aprendidas através da análise dos Cramis. A primeira é que as famílias que vivenciam a violência doméstica não devem ser vistas como dicotomicamente divididas entre vítimas e abusadores. O agente agressor também deve ser envolvido na atuação, assim como os demais familiares. Conclui-se que a atenção deve ser integral à família, e não somente à criança e ao adolescente abusados.

Em segundo lugar, a experiência dos Cramis adverte que a criminalização da família ou do agente agressor como princípio para a atuação constitui-se apenas em um paliativo para o problema e pode, em contrapartida, ser um fator de desagregação familiar. A família que experimenta os maus-tratos, contanto que devidamente atendida, continua a ser a principal referência afetiva para aquela criança ou adolescente.

O terceiro ponto é a constatação da complexidade da violência doméstica. $\mathrm{O}$ contato com as famílias maltratantes mostra uma série de questões distintas que reforçam as condições 
predisponentes às relações familiares violentas: desemprego; condições de pobreza ou empobrecimento; valores culturais que justifiquem condutas violentas; conflitos conjugais; problemas psicológicos e afetivos; alcoolismo; falta de serviços básicos, como creches, escolas, habitações condizentes com as necessidades das pessoas que aí convivem - estes são alguns dos dados concretos no dia-a-dia de muitas destas famílias. Por outro lado, a vivência direta com os maus-tratos e suas conseqüências, a curto, médio e longo prazos, indica que, para um único serviço isoladamente, é impossível empreender uma atuação que redunde em algum impacto.

Há a necessidade, portanto, da consolidação de uma atuação em rede que integre vários equipamentos sociais. A atuação interinstitucional, mais que um princípio, é uma necessidade diante da complexidade do problema. A parceria entre os equipamentos do Estado e da sociedade civil, aliada ao envolvimento com a comunidade, é uma medida de absoluta necessidade na atuação junto às famílias que vivenciam a violência doméstica.

Outro aspecto importante é a atuação de uma equipe que conjugue a experiência de vários profissionais ligados a diferentes áreas. A equipe multiprofissional - com psicólogos, médicos, assistentes sociais, entre outros — , favorece uma atenção mais completa aos distintos problemas e necessidades envolvidos na questão da violência doméstica.

Por fim, a experiência dos Cramis alerta para o fato de os distintos tipos de abuso terem características diferenciadas e necessitarem de um trato adequado a estas peculiaridades, ainda que regido por um princípio geral.

A análise da atuação dos Cramis aponta sobretudo para a viabilidade da atuação junto às famílias envolvidas com os maus-tratos e demonstra, nos 9 anos de trabalho e mais de 6.000 casos atendidos por estas instituições, que é realmente possível interceder no problema.

Em resumo, os pontos mais sugestivos da contribuição da experiência dos Cramis para a discussão nos serviços de saúde seriam os seguintes:

a. tomar a família como o alvo da atuação;

b. envolver os vários serviços e instituições, criando uma rede de atuação; c. ter na visitação domiciliar uma estratégia de ação;

d. trabalhar junto com os serviços da vizinhança onde a família vive (escola, posto de saúde, associações), a fim de estabelecer uma ação de vigilância das reincidências;

e. não criminalizar a família e considerar como essencial o investimento na atenção ao ambiente familiar, tomando-o como o espaço como o mais conveniente para o crescimento e desenvolvimento da criança e do adolescente.

\section{RESUMO}

DESLANDES, S. F. Atenção a Crianças e Adolescentes Vítimas de Violência Doméstica: Análise de um Serviço. Cad. Saúde Públ., Rio de Janeiro, 10 (suplemento 1): 177-187, 1994.

Este artigo efetua uma síntese parcial do estudo "Prevenir e Proteger: Análise de um serviço de atenção à criança vítima de violência doméstica". A pesquisa analisou a atuação dos Centros Regionais de Atenção aos MausTratos na Infância (Cramis) no atendimento a crianças e adolescentes (e familiares) vítimas da violência intrafamiliar. Buscou-se um diálogo teórico-metodológico entre as abordagens quantitativa e qualitativa, focalizando a estrutura, os processos e as representações presentes na atuação dos Cramis, além da caracterização das famílias atendidas no período de 1988 a 1992.

Apresenta-se como resultado o perfil dessas famílias, bem como o perfil de atuação dos serviços. Diante dos dados analisados, discute-se a potencial contribuição da experiência dos Cramis à implementação de ações no sistema público de saúde.

Palavras-Chave: Violência Doméstica; Violência Contra a Criança; Saúde da Criança; Saúde do Adolescente 


\section{REFERÊNCIAS BIBLIOGRÁFICAS}

ASSIS, S. G., 1991. Quando Crescer é um Desafio Social: Estudo Sócio-Epidemiológico Sobre

Violência em Escolares da Duque de Caxias, Rio de Faneiro. Tese de Mestrado, Rio de Janeiro: Escola Nacional de Saúde Pública, Fundação Oswaldo Cruz.

AZEVEDO, M. A. \& GUERRA, V. N. A. (Orgs.), 1989. Crianças Vitimizadas: A Síndrome do Pequeno Poder. São Paulo: Iglu.

CONDON, J. T., 1986. The spectrum of fetal abuse in pregnant women. The Fornal of Nervous and Mental Disease, 174: 509-516.

CRAMI (Centros Regionais de Atenção aos MausTratos na Infância), 1992. Documento de Divulgação. Campinas: Crami. (Mimeo.)

GARBARINO, J. \& GILLIAM, G., 1981. Understanding Abusive Families. Massachusetts: Lexing Books.

GIOVANNONI, J. M. \& BECERRA, R. M., 1982. Defining Child Abuse. New York: The Free Press.

GELLES, R. J., 1979. Family Violence. Beverly Hills/London: Sage Publications.

GIL, D., 1978. Violence Against Children: Physical Child Abuse. $8^{\text {th }}$ ed., Cambridge: Harvard University Press.

GUERRA, V. N. A., 1985. Violência de Pais Contra Filhos: Procuram-se Vitimas. São Paulo: Cortez.

IBGE (Fundação Instituto Brasileiro de Geografia e Estatística), 1990. Síntese de Indicadores $d a$ Pesquisa Básica da PNAD de 1981-1989. Rio de Janeiro: IBGE.

JUSTICE, B. \& JUSTICE, R., 1976. The Abusing Family. New York: Human Sciences Press.

KLEIN, C. H. \& COUTINHO, E. S. F., 1988. Confiabilidade de Diagnósticos Psiquiátricos. Um programa prático para microcomputadores. Fornal Brasileiro de Psiquiatria, 37: 51-54.

MEYER, M. P., 1988. Violência Contra a Criança: Uma Questão Emergente. Tese de Mestrado, Rio de Janeiro: Pontifícia Universidade Católica do Rio de Janeiro.

MINAYO, M. C. S. (Org.), 1993. O Limite da Exclusão Social: Meninos e Meninas de Rua no Brasil. São Paulo: Hucitec/Rio de Janeiro: Abrasco.
MONTEIRO, M. C. N., 1992. Estudo Descritivo de Aspectos Psicossociais de Pais e Responsáveis Agressores de Crianças e Adolescentes Atendidos no CRAMI Campinas. Tese de Mestrado, Campinas: Universidade Estadual de Campinas.

MS (Ministério da Saúde), 1991. Estatuto da Criança e do Adolescente. Brasília, DF: Ministério da Saúde.

NCCAPR (National Center on Child Abuse Prevention Research, 1992. World Perspectives on Child Abuse: An International Resource Book. Chicago: NCCAPR (Mimeo.)

OATES, R. K.; PEACOOK, A. \& FORREST, D., 1984. Persisting characteristies of parentes of battered children. The Medical Fournal of Australia. 140: 325-329.

OLDS, D. L. \& KITZMAN, H., 1990. Can home visitation improve the health of women and children at environmental risk? Pediatrics, 86: 108-116.

OLIVEIRA, W. F., 1989. Street Kids in Brasil an Explanatory Study of Medical Status Health Knowlodge and the Self. Tese de Mestrado, Minnesota: University of Minnesota.

RUIZ, Z. A., 1985. Dinâmica familiar e o abuso da criança. In: A Criança Maltratada (S. Krynski, org.), pp. 41-52, São Paulo: Almed.

SABOIA, J., 1993. Distribuição de renda e pobreza metropolitana no Brasil. In: Limites da Exclusão Social: Meninos e Meninas de Rua no Brasil (M. C. S. Minayo, org.), pp. 31-64, São Paulo: Hucitec/Rio de Janeiro: Abrasco.

SANTOS, H. O., 1987. Crianças Espancadas. Campinas: Papirus. FCBIA. , 1991. Crianças Violadas. São Paulo:

STRAUS, M.; GELLES, R. J. \& STEINMEDZ, S. K., 1980. Behind Close Doors: Violence in the American Family. Garden City: Anchor Press.

TORTORA, R. D., 1978. Note on sample size estimation for multinomial populations. The American Statistician, 32: 100-102.

U.S. DEPARTMENT OF HEALTH AND HUMAN SERVICES, 1991. Family Violence: An Overview. Washington, DC: U.S. Department of Health and Human Services. (Mimeo.) 